\title{
South Sudanese or Australian or Both or Caught in Between? A Qualitative Study Examining Identity Among South Sudanese Refugees Living in Sydney, Australia.
}

\section{Geraldine Vaughan ( $\nabla$ g.a.vaughan@cqu.edu.au)}

Central Queensland University, Australia, School of Health, Medical and Applied Sciences, College of Science and Sustainability

\section{Tafadzwa Nyanhanda}

The University of Notre Dame Australia, Melbourne Clinical School, School of Medicine

\section{Sabitra Kaphle}

Central Queensland University, Australia, School of Health, Medical and Applied Sciences, College of Science and Sustainability

\section{Jenny Kelly}

Central Queensland University, Australia, School of Nursing, Midwifery \& Social Sciences

\section{Lal Rawal}

Central Queensland University, Australia, School of Health, Medical and Applied Sciences, College of Science and Sustainability

\section{Mude William}

Central Queensland University, Australia, School of Health, Medical and Applied Sciences, College of Science and Sustainability

\section{Research Article}

Keywords: South Sudanese, refugee, Australia, identity, migration, employment, discrimination

Posted Date: December 1st, 2021

DOI: https://doi.org/10.21203/rs.3.rs-1112825/v1

License: (1) This work is licensed under a Creative Commons Attribution 4.0 International License. Read Full License 


\section{Abstract}

\section{Background:}

The majority of the current South Sudanese population in Australia arrived as refugees in the early 2000s, facing challenges related to dislocation, navigating a new culture while honouring their own own. Much of the research on the South Sudanese experience has been conducted in the early years after arrival, with resettlement stressors likely to influence narratives of identity as new immigrants.

This study aimed to understand the lived experiences of identity among South Sudanese who are longterm residents of Australia after fleeing their birth country, migration, and re-building their lives.

\section{Methods:}

The qualitative study was underpinned by a phenomenological framework that characterised the experiences of study participants. Purposive and snowball sampling was used to recruit Sydney-residing adults who arrived in Australia through its humanitarian refugee program 10 or more years ago and were born in South Sudan. Semi-structured interviews explored how participants identified themselves in Australia, changes in their experiences over time, their social and general life situation in Australia, and perceptions (self and other) of South Sudanese people in Australia.

\section{Results:}

The 26 participants from refugee backgrounds all had similar experiences of dislocation, most arriving in Australia 10-19 years ago with family members. Most participants were in employment and had attained (sometimes multiple) educational qualifications.

Participants described a multiplicity of interconnected domains that governed the negotiating and making sense of identity. Three key themes were identified: mutable identities - dependent on context; Identity in relation to children; and the influence of limited opportunities. These themes were mediated by other interwoven personal and structural factors that shaped experience and perception. Expressions of hope, pride and achievement were threaded through several of the interviews, particularly in relation to their children. There was also frustration related to employment challenges and discrimination that limited identity reconstruction.

\section{Conclusions:}

Our exploration of long-term lived experiences for South Sudanese migrants highlights the evolving and often conflicting factors that shape domains of integration and identity construction.

The deeper, more nuanced understandings of bicultural identity within a strengths-based framework calls for better partnerships and services to support strengthened community and acculturalisation. 


\section{Background}

Continuing migration has led to increasingly diverse cultures and languages in Australia, with immigrants facing questions concerning their bicultural or multicultural identities (1). Identity may be defined as "the totality of one's perception of self, or how we as individuals view ourselves as unique from others". Individual identity is contextual, culturally, and structurally determined; and tied to a matrix of social roles, statuses, groups and networks (2).

The process of negotiating multiple cultural identities is complex and multifaceted. Acculturating immigrants and ethnic minorities often have to navigate two central issues, i) 'cultural maintenance,' the extent to which they are motivated or allowed to retain their heritage identity; and ii) 'intercultural contact,' the extent to which they are motivated or allowed to identify with the culture of their receiving country (3). When an individual is embedded in a community that integrates the heritage and receiving cultural streams - that is, the culture of the country in which one has settled - there is a holding of values, acceptance and identity consistent with the two cultural contexts $(4,5)$. It is well acknowledged that heritage identity across generations persists (6) and that identity, as conceptualised by the individual in question, may vary depending on the life domain of interest $(7,8)$. This dynamic nature of identity increases interest in understanding the experiences of people living outside their culture of origin $(9,10)$.

Challenges relating to health, education, employment and identity escalate among refugee populations $(11,12)$, and this burden is increasing against a backdrop of the steadily increasing global refugee crisis.

In the Australian context, migration policy stances have been shaped by ambivalence and hostility at different time points (13-17), with resettlement factors such as racism, sense of community and social isolation all influencing and shaping cultural identity and congruity $(18,19)$.

In addition to the issues common to refugee and migrant populations, such as language, navigating a new culture and systems while honouring their own culture (14), South Sudanese communities have experienced particular challenges. Most of the current South Sudanese population came to Australia as refugees in the early 2000s (Department of Social Services, 2018). A significant portion of the community has now been in Australia for more than ten years and has begun the process of acculturation and integration into Australian society. This same period is sufficient for developing a bicultural identity combining elements of the heritage culture of community members with a new identity as part of the Australian population (5).

While work has been conducted in other Australian jurisdictions exploring South Sudanese identity perspectives $(14,20-24)$, there is less equivalent in Sydney, Australia's largest city. Moreover, much of the research in other states was conducted shortly after the South Sudanese arrived in Australia and resettlement stressors are likely to have heavily influenced their narratives of identity as new immigrants.

This study examines the perception and experience of identity for South Sudanese who have lived in Sydney, Australia, for ten years or more. Some narratives of this community in the popular media and 
political commentaries have depicted them as people who are not integrating into the Australian community, involving an explicit or implicit process of divisive racialization harmful to the sense of identity and belonging in the community $(14,25-27)$. What are the identity constructs of South Sudanese living in Sydney, and how do the elements of a dual identity as a social determinant of health shape their physical and mental health, resilience, and adaptation to the Australian context following migration? Our research aims to bring voices of the South Sudanese community into this discourse, providing insight into their perspectives and experiences of migration and a depth of understanding of the role of heritage identity in the Australian context in Sydney. This understanding is vital to informing policies and services that better support a strengthened sense of belonging, improved resettlement outcomes, health and social well-being.

\section{Methods}

\section{Theoretical framework}

A conceptual framework underpinned by a rights-based approach developed by Ager and Strang (2008) was used to characterise the experiences of study participants. In this schema (Figure 1), four key themes were identified that defined core domains of integration (28). First, Ager and Strang posit that 'markers and means' such as employment, housing, education, and health were important for constructing concepts of belonging. Following this was a sense of social connection (second stage) a person has in their new community, including building social bridges, social bonds and social links. The third stage involved facilitators such as language and cultural knowledge and a sense of safety and stability. The fourth and last domain was centred around a person's foundation in a new place in the form of the rights they enjoy and their citizenship status. This framework posits that individual senses of identity and belonging are centred around these core domains. Ager and Strang's framework is well recognised and the most referenced on studies about identity, belonging and integration (see for example, (29-32).

Reproduced with permission Ager and Strang (28)

\section{Study design}

The qualitative study design was underpinned by a descriptive phenomenological framework that aimed to understand the lived experiences of identity among adult South Sudanese refugees after fleeing their birth country (often forced and traumatic), migration to Australia, and re-building their lives, who had resided in Sydney for 10 years or more.

\section{Study setting}

This study was conducted in metropolitan Sydney - the largest city in Australia, with a population of approximately 5.4 million people (33). One in three Sydney residents are born overseas, and about $21 \%$ 
speak a language other than English at home (34), reflecting the cultural and linguistic diversity of the city. Since the year 2000, South Sudanese have resettled in Australia under its humanitarian refugee resettlement program, with just over 1,000 NSW residents listing South Sudan as their country of birth (35)

\section{Recruitment and sampling}

Purposive and snowballing techniques were employed to recruit participants who responded to advertisements through community leaders, community workers, community social media groups and community-based organisations. These stakeholders were provided with explanations about the aim and scope of the study and were asked to invite community members to participate in the study. Interested participants contacted the researchers directly to arrange for an interview. Participants then referred someone they knew in the community to contact the researcher. Potential participants were directly approached by these community leaders and community members, asking them to participate. Participants were included in the study if they:

1. Were aged 18 years or older;

2. Had lived in Australia for at least 10 years; and

3. Were not born in Australia and identified as of South Sudanese heritage.

All but one participant (who was not included due to relocation from Sydney) that contacted the researcher participated in the study. A $\$ 50$ gift voucher was offered to participants to acknowledge their time commitment.

\section{Interviews}

Semi-structured interviews were conducted in 2020 and 2021 with twenty-six adult South Sudanese individuals (19 males and 7 females), six face-to-face (before COVID-19 social distancing regulations were introduced) and 20 interviews via telephone. All face-to-face and phone interviews were conducted by WM, an experienced qualitative researcher, and a new member of the South Sudanese community in Sydney. None of interview participants were previously known to WM. According to participants' preferences, all but two interviews were conducted in English, with two participants speaking English and Juba Arabic (a commonly spoken form of Arabic among South Sudanese people) interchangeably. Each of the semi-structured interviews lasted between $45-90$ minutes. They explored how participants identified themselves in Australia, what makes them identify themselves the way they did, their experiences of settling in Australia, changes in their experiences over time, social and general life situation in Australia, the perceptions of South Sudanese people in Australia, and how they saw themselves and that of the general South Sudanese community in Australia. See Supplementary material 1 for Interview guide. The interviews were digitally recorded with participants' consent and subsequently 
transcribed (by a member of the community who is a trained and certified bilingual interpreter) and anonymised.

\section{Analysis}

Data were analysed thematically (36) in stages by WM, GV and TN. First, the researchers familiarised themselves with the data, reading a designated number of transcripts and drafting a coding framework to achieve consistency. Independent coding of the data was then conducted, followed by further discussions to identify similarities and divergences, and a consensus was reached to resolve any differences between and among the independent analyses. Third, the codes were consolidated into themes that illuminated the experience of identity among the South Sudanese people. The last stage of the analysis involved interrogating the themes for their relevance and how they fit into the existing literature. Regular meetings were held among co-authors to critique the process and analysis and discuss emerging findings. NVivo software was used to assist with the coding process of the interview data.

\section{Ethical approval}

Ethical approval for the study was granted by the Human Research Ethics Committee of Central Queensland University (Approval Number: 22101). All face-to-face participants provided written consent before taking part in the interview. However, when social distancing regulations were introduced in Sydney because of COVID-19, the ethics application was modified to allow for data collection and verbal consent given over the phone prior to interviewing. Before commencing the interviews, issues relating to confidentiality, data anonymising, and opting out of the study were reviewed with participants. Notetaking was not conducted in order to facilitate a conversational flow that focused on participants and their narratives.

\section{Results}

\section{Participant characteristics}

Although all 26 participants had similar experiences of dislocation, they differed in their trajectories of the migration process. Participants came to Australia from different countries of asylum, including Uganda, Kenya, Syria, Egypt, Ethiopia, and Lebanon, and these came to inform their migration experience. A majority of them came with family members. Most had arrived in Australia 10-19 years ago, with three participants residing 20 or more years. See Table 1 below for participant characteristics, including age group, gender, years in Australia. Most participants described completing (often multiple) educational qualifications, with the majority in employment. Several described their active roles in the South Sudanese community involved in advocacy and community-building.

Table 1: Participant characteristics 


\begin{tabular}{|c|c|c|c|c|}
\hline Gender (n) & Female (7) & Male (19) & & \\
\hline $\begin{array}{l}\text { Age group (n) } \\
(\text { not stated } \times 1 \text { ) }\end{array}$ & $21-30(5)$ & $31-40(5)$ & $41-50(9)$ & $\begin{array}{l}51+(6) \text { oldest } 64 \\
\text { years }\end{array}$ \\
\hline $\begin{array}{l}\text { Time in Australia } \\
(\mathbf{n}) \\
\text { (not stated } x 1 \text {; } \\
5-9 \text { years } \times 1 \text { ) }\end{array}$ & $\begin{array}{l}10-19 \text { years } \\
(20)\end{array}$ & $20-29$ years (4) & & \\
\hline $\begin{array}{l}\text { Arrived in } \\
\text { Australia (n) }\end{array}$ & By self (4) & $\begin{array}{l}\text { With family or } \\
\text { family } \\
\text { already here (18) }\end{array}$ & $\begin{array}{l}\text { With } \\
\text { friends/community } \\
\text { (1) }\end{array}$ & Not known (3) \\
\hline
\end{tabular}

Participants described a multiplicity of interconnected domains that governed the negotiating and making sense of identity. Three key themes were identified:

- Mutable identities - dependent on context;

- Identity in relation to children - the 'next generation';

- Opportunities and constraints limiting identity reconstruction

These themes were mediated by other interwoven personal and structural factors that shaped experience and perception (Figure 2).

\section{Mutable identities, dependent on context}

Identity was shaped by a matrix of influences that inevitably developed over time and was contextually driven. This contingent identity and adaption were woven into participants' stories of arrival, resettlement challenges, family, work and community. Narratives of building lives in Australia helped explain how they negotiated shifts in cultural identities and how this evolved. The age at which participants arrived influenced perspectives, with some of those who had arrived as children commenting that they felt it was easier for them than their parents.

\section{Ambivalence, contradiction, context}

Identity was defined by circumstance and environment, with participants reflecting how this shifted over time and according to the physical location. Most talked to some degree about learning to move across invisible demarcations of identity, according to work, community and family life.

This process was framed beyond rationality: it was grounded in values, spirit, heart. For some, this was expressed as a shifting identity to the country where they had lived for most - if not all - of their adult 
lives. They described it as 'a feeling thing' [P1], reflecting on physical appearance and identity, contrasting how they looked and now felt in Australia ("looking like the minority but feeling in the majority) and their birth country of South Sudan ('looking like the majority but feeling in the minority). [P1]

Ambivalence and contradiction were evident: an Australian identity was the 'other' for several, with references to 'them', 'they' rather than 'us' and to 'fitting in': "What's... being an Australian? I think it's just fitting in into their culture." [P6] One described themselves as primarily Australian in identity initially in the interview but then later as being more Sudanese "... which probably contradict[s] what I said earlier but this is $m e^{\prime \prime}[\mathrm{P} 23]$

Having 'two legs' was described, and that there were elements of not fitting in wherever they were:

It's a very confused identity and it is defined by the context you are in. So, if you are in Australia, you pretty much think that you are a South Sudanese, but the way you feel might be different. And there is no way to test that unless you leave Australia and go back to South Sudan or Africa. And then you realize that you don't belong there either, so that's how I see myself. [P1]

For others, their sense of location and belonging was embedded in the land that had raised them: South Sudan was the country in their heart [P11] [P17]. They felt that life was rich back in their birth country, with connection to land and community ownership supporting an attachment to spirit and ancestors. "We even have our own hunting place ... So I feel like I'm still attached there with the spirit and everything... It's because we feel that we all should have lands, and our ancestor and great, great ancestor and everything, [where] their blood [was] buried" [P17]

\section{Civic rights and responsibilities: citizenship and identity}

Identity was linked to a sense of contributing to a country: to its economy and society, building the next generation and adopting values; citizenship in the context of civic responsibilities as well as rights.

I also see myself Australian because I participate in the economy. I'm contributing equally as any other Australian person born in Australia. To the economy, I pay my tax and I'm working. And so, I also have a son here in Australia. So, I see myself as Australian. [P3]

Citizenship straddled two cultures ... "Regardless of the citizen I become, and regardless of any other thing that I may enjoy here, for example, in Australia, I will not forget my identity, my roots, regardless of anything. Here in Australia, I am part Australian at the same time, because l've got rights to do everything." [P12]

Responsibilities to the community were described by most but varied whether this was primarily to Australia or Sudan. For one, their giving back was to their people in South Sudan "... who contributed in my life... That's why I always feel I still belong there" [P11], while others spoke of their (now) primary obligations to Australia. A divergent perspective argued for the imperative to stay in Australia rather than 
going back to post-war South Sudan: there was an imperative to build a 'good community' in their new home for the next generation [P4].

The mutuality of this responsibility was referred to by some, who stressed that a capacity to contribute and build identity developed over time. Being refugees meant they came to Australia under difficult sometimes horrific - circumstances and often without a support base with which to start their life. "They need support. And they need to be well. To feel that they are welcome in the country" described one, in order to be able to contribute as equally as any other person. [P3]

\section{Identity in relation to children: the 'next generation'}

A strong theme threaded through most participants' narratives was the consideration of identity in relation to their children. Expressions of hope, pride and achievement [P4][P18][P21][P24], were threaded through several of the interviews, particularly in relation to their children: "I think that there's a great hope, generally, yeah, it is a great hope, especially for kids" [P21]. They differentiated their own identity from that of their children at several levels: '...so basically, I'm more of actually South Sudan than Australia, but my children would be different.' [P17]

There were mixed views about their children growing up: wanting their kids to be easy with their own identity in Australia, but to also hold close to their culture and heritage. Parents grappled with anchoring kids - and being anchored - within and across their dual identities: cultivating a nourishing 'glue into oneself' for children [P23] that connected them back to Africa and South Sudan. They feared not being around to protect their children from racism, referring to their own resilience forged from past experiences and doubting if their children would feel as anchored "...because when I'm not here and they are told that they are not Australian, I don't know how they will feel because they have not been formed by what formed me." [P1]

Gender-based themes related to identity were discussed in the context of children and traditional family roles. Men described being challenged to step out of their own traditions and changing divisions of labour within the family [P4][P9][P13][P17]. There were concerns expressed about changing roles in relation to daughters [P4][P21].

For ... a girl when they move out of the house, that is the time you're getting married ... But here now, somebody gets into 20 or 22, they want to move out of the house. It's like such a shock for us parents... maybe they went out because of the education, or maybe they'll go out because for the nature of the job they're doing. But sometimes we as parents we look at it like it's not a good thing. ... Yeah, these are some of the things that mean ...parents to be educated how life is here different... How are we to prepare them at that stage? .... So it's very challenging for us parents. [P21]

Participants expressed conflicted perspectives, recognising that their own ambivalence was not reflected in their children, who were more grounded in an Australian identity. One parent spoke of returning with 
their children to a post-war South Sudan "...if all the best come to the best", taking what had been learnt in Australia to help rebuild the country. Yet, later in the interview, this participant acknowledged that, while they themselves felt more South Sudanese than Australian, they knew their children were different. [P17]

Parents wanted their children to hold onto a bicultural identity with pride, referring to two cultures, dual citizenship, two identities. "And he should feel head up that he has two cultures. That's important. Some people only have one culture. He has... African culture. And also the Sudanese cultures. And also the Australian culture. So, that these ... unite together. And then yeah, that will make him to be who he is". [P3] Culture as a two-way adaptation and learning process was discussed in the context of Australian multiculturalism, "... because this is a multicultural country, I also have to make sure that my culture is also implemented where I am here". [P13], as well as questioning how children could hold onto to their traditions: "So how can we make it that we bring up kid in a multicultural society not a South Sudanese traditional way of upbringing?" [P4]

Others described their children interacting with and identifying more with other African young people, gravitating to a pan-African identity in order to form the support amongst themselves - as a consequence of being "lumped into this one homogenous [African] group and they're victims of discrimination". [P19]

Differing perspectives were introduced by participants who had arrived as children and grown up in Australia, with one reflecting that, while he felt comfortable in his identity, he did not see the older generation sharing that... "I feel like the older generation who, I guess, brought the kids here, are [here] just basically for the sake of the kids. I don't think they're as happy as us."... "And often they're talking about going home when they retire." [P5]

\section{Preserving culture - across the generations}

Strategies to maintain continuity of cultural identity and structure across generations included both formal (youth rallies, language classes) and informal (community social gatherings) initiatives. Instilling a knowledge and pride for children about cultural heritage was imperative to build cohesive communities and "...to know exactly the root of the parents... And they're going to explain also to those [next] generation..." [P25]. Another spoke of passing on their oral history and lineage to children:

[My children] try to make their own family tree. And I said..., "You don't need to make a phone call to make a family tree because I can still read back five generation, so you just copy what I'm giving you because I'm still the living biological tree." [P17]

This continuity of cultural identity required commitment and not being 'quiet': the first generation born in Australia needed to know their origins, and in particular, their culture, to pass on lest in time it disappeared

"...just within maybe two generations, when they start producing their children, those children, they don't know their grand grand, or great parent came from, because we shall not be there anymore". [P25] 
Strong community was stressed as being critical to this continuity [P19]. Another participant spoke of their community's strength of identity, forged by the legacy of their country's struggle and trauma:

So as South Sudanese, we have ... experience that is defined by struggle: personal struggles and collective struggle... But generally, the way most of us from the South Sudanese community see things, we are very strong when it comes to identity because, in the first place, that's what brought us here. [P1]

Generally, participants called for stronger cohesion among their community, some reflecting on what they saw as a weakening of bonds over time. They reflected that, along with the growth of the Sudanese community over the last twenty years, came divisions in tribal lines that had not existed on first arriving. [P12] It was felt more effort was needed to build harmony: "There's no need for us to be fighting each other in this land as well". [P16] They pointed to examples of other immigrant community successes as being founded on working together, advocating for their community, championing each other in work, study, community. "When one is holding other person's hand to lift them up, we will all rise up. [P16]

\section{Language and identity}

Holding on to language was seen as a critical part of this next-generation identity, particularly in the context of stories, traditions and culture: their 'backstories':

... back home in Africa, ... parents come and sit together close to the fire. They tell the children the stories, how they used to be, and the kids keep listening to it. And at the moment, this is what I actually do to my children, for them to know their own culture or their backstories. Who their grandparents are, what do they used to do, and do they used to do all of this? And the most important thing that I like here right now is, I always speak to my kids here in the dialect. I always tell them that our dialect is the first language. You have to learn it. [P13]

That is storytelling. It helps them in future to know where their parents originate from. They will know the root of their parents. [P15]

The challenges of retaining birth language(s) were reflected on, particularly in settings where there were multiple languages spoken in family and community [P18]. Marriages and partnerships were described where English was the common language spoken, even for South Sudanese parents from different tribes [P11, P4, P12]. Parents spoke of teaching children Juba Arabic and other South Sudanese languages, but acknowledged this was challenging "... so my kids are confused, to be honest." [P11], “...but the kids are $100 \%$ into English... So we're trying to push onto our language for them to learn it, but it's a journey." [P12]

Another parent wanted their children to understand their language as part of their background "It's very important because language is the origin of the culture...Plus, it is just a tiny bit of us here" [P18] - but also other languages "For a kid, they have ability to learn different languages. So if they can know my language, plus English, other languages, that's fine". However, this was viewed in an overall context of identity and belonging which was ultimately up to the children: "So it would be up to [the children] to 
identify as South Sudanese or as Australia. But my only thing is to make sure that I educate them to be a good citizen of Australia." [P4]

Holding onto their birth language was important for participants themselves, who described using a mix of dialects, Equatorian languages (particularly Juba Arabic) and English according to setting: "So because... I'm a Madi, then I see a brother from Madi, then I just feel I need to speak to him in the language."[P12]

\section{Opportunities and constraints limiting identity reconstruction}

\section{Education and employment}

Participants spoke of the linked centrality of (access to) education and employment with identity and agency. Several participants spoke appreciatively of their access to and support for education and living, including mentoring, and how this instilled confidence and a sense of contribution to community and family "... it feels much better, good, like a human being now I feel like a grown up." [P21] "Education is not for everybody, but it seems to be the best way if you want to be successful. [P7] "Then you feel like you're now even contributing to the family or even to the community." [P21] One mother spoke of her drive to support her children's education with assistance: "And then good food and then the government give, when you are a single mom, they give you support money. And then you can't even hear the guns around. This is very important." [P10]

Frustration was expressed by some, who felt that access to education was not matched by their employment opportunities. They spoke of what felt like insurmountable struggles to get their first job "... after you went through all 100 agencies and they said one thing, so you come back and you say to yourself, "What do I do now?", reflecting that they survived and did get work, describing the resilience they built in 'passing it' [P4].

Another described completing multiple degrees (with attendant student loan fees accumulating) before they were able to find themself in the workplace [P8]. They were frustrated at not being able to work in their field of specialization with the inevitable loss of skills and knowledge from a degree that was not being used. Describing underlying discrimination, this participant advocated for volunteering to prevent protracted unemployment and cut through what they saw as the first-job barrier [P4]. Lobbying a Prime Minister to leverage votes for improved work opportunities was given as an example of a situation where discrimination precluded employment in a regional town, with participants having to travel four hours away for paid work. [P11]

Another participant who arrived in Australia as a child and otherwise described feeling comfortable with both South Sudanese and Australian identities matter-of-factly commented that ..."I always have to push to be better than my white counterparts, because I just know that they'll pick them over me if I'm not better 
than them." [P5] This was commonly referred to, with one describing the financial and family stressors in the context of education and work constraints and discrimination [P7]. One parent felt that the lack of educational qualifications in their community had a limiting influence on their children, who, she felt, had little motivation to attain post-secondary formal education [P18]. Acknowledging these challenges, another spoke of their determination in preparing for their 'second place here in Australia', not taking anything for granted. [P12]

Parents and community leaders were called on to counter what they saw as limited education opportunities through community-based tutoring initiatives. They urged parents to support their children, strengthening education and career opportunities... "And then we leave the generation to them." [P13][P16]

\section{Racism limiting identity reconstruction}

Discrimination and racism challenged identity formation. This was experienced in many ways, occasionally overtly but often more subtle. It ranged from being told to 'go back to your country' as a child, to persistent questioning of 'where are you from' to feeling 'other', to what was seen as discriminatory media portrayals, to limited work opportunities.

There were different responses among participants relating to the question 'where are you from', with most feeling the question was inappropriate and usually laden with racist overtones. When responding with their neighbourhood home residence, participants were further prodded to identify their country of origin. Some spoke of responding differently according to who asked the question, while others gave the transit country to which they fled as their country of origin "Because people look down if I say I'm from Sudan." [P7]

Even now, how many people ask me, "Where are you from?" And then I say I'm from Penrith. And somehow they think that I'm trying to play some trick ... And then I realize, "Oh, they want me to say I'm from South Sudan." [P1]

These are silly questions they ask. Even us we don't ask them. We don't ask these white people where do you come from? [P8]

Others described the racism being deflected with dignity, particularly by those who had been in Australia for longer periods of time [P1, P12], "The tone of the asking is not really wanting to know where you come from, but I tell them proudly I come from South Sudan, and I'm an Australian. ... Then I question them.. "What about you, where are you from?" [P12]

Racism contributed to a lack of belonging and aversion to living in Australia. Citizenship did not stop this sense of being 'other' for some: "But basically, I know majority of the white people, they don't consider you as being Australian completely. They see you half way, they see you more, say $75 \%$, if not $100 \%$ as from somewhere else, although you have the citizenship." [P17] Others felt simply that they were not welcome "...Because when somebody said to you go back to your country, that means this is not your country... 
That means, even though how much we contributed into the economy, we studied very hard, we're working very hard... like any other Australian person." [P3]

Several commented on negative media portrayals of South Sudanese and how this influenced and reinforced stereotypes. Frustration was expressed that, while coming from "a broken world" [P16], the violence described by media was not realistic. These portrayals leaked into 'everyway' - work, getting jobs, community relationships: "You have to try and convince them more that you're not what the TV is saying or what your image is being put out to be" [P6]. Parallels were drawn with other communities that had experienced similar discriminations and stereotyping: there were lessons learnt, they felt, in looking to how Lebanese communities had addressed antipathy and discrimination in the media. Strong, cohesive leadership from all-African communities speaking with authority and one voice [P23] was called for to shift reporting and stereotypes.

Central in this narrative was the impact on children: the fear of discrimination extending to participants' children, confining aspirations and ambitions for the next generation. Countering discrimination was thus seen as critical in order to support generations to come "...to turn that page. Because if we don't do it today, our children indeed [will] be seen the way they also see us today " [P12].

While for most participants, a gradual process of adapting identity was described, for one, it was more dramatically related to a visit back to South Sudan, which triggered a shift in nation-identity perception as well as confidence in countering racism:

So when I came back [to Australia], I felt more Australian ... Before I went back [to South Sudan] in 2007, if someone tells me on the street, "Go back to where you came from," I'll say, "Yes, I'll go back to where I come... I know where I came from." But after that, my feeling changed after coming back. So, if someone talked to me in a way that made me feel that I don't belong here, I fight more. [P1]

Self-reliance and direction were also described ... "In Australia, life you're the one who make it easy, you're the one who make it difficult in Australia." [P14]

\section{Discussion}

While much has been written on recent resettlement experiences of South Sudanese in the context of trauma and hardships fleeing a war-torn country, there is little exploring the journeys and identity construction for South Sudanese who are long-term residents and citizens in Australia. As a relatively small demographic, this population is significantly affected by disparities in the major social determinants of health (Noam, 2016). Challenges in identity reconstruction and strategies in acculturation and identity adaptation were described by participants in our study, who were often faced with ambivalence as they navigated core domains of integration as defined by Ager and Strang (28).

Underpinning markers and means - employment, housing, education, health - were variously described in supporting a sense of belonging. Reflections on social connection, language and cultural facilitators and 
citizen rights, status and responsibilities similarly varied. Temporal shifts were noted, with many participants describing changes over time in how they experienced key domains of identity and integration. As refugees, South Sudanese have usually come to Australia after extended periods in refugee camps, often under challenging situations (20). Participants recognised the importance of time needed to establish themselves, build and rebuild their identities and make what they saw as notable contributions to Australia.

Education, employment and belonging are important determinants of health $(37,38)$, and critical underpinnings of integration in a new society (28). Access to formal education opportunities in Australia was described with appreciation, instilling a sense of empowerment and hope. However, these opportunities were generally not matched in the work setting: structural barriers constrained employment options, particularly in participants' early attempts. Although most participants were engaged in work, a lack of employment and underemployment were both described, which negatively affected their health and integration. Self-reliance and employment are vital underpinning determinants of dignity, social capital and identity-formation. The barriers described in this study are consistent with other refugee experiences $(20,39-41)$, and shape their ability to participate in health-promoting activities (42). Employment barriers were exacerbated considering the youth of South Sudanese, with most arriving in Australia under 25 years of age. Our findings on the relationships between identity formation in relation to work for refugees in different countries are not unusual (43-48). Wehrle et al describe how multiple integration barriers in relation to work and society can also threaten refugees' fundamental identity needs for worth, distinctiveness, continuity, and control (49). These complex matrices of influences of identity as they relate to work agree with our findings, along with the call for stronger support mechanisms to facilitate employment opportunities and reduce postmigration stress, particularly in the early years of arriving (50).

Many participants in this study felt they were both Australian and South Sudanese. Australian identity was perceived through contribution to the economy, attaining education, buying houses, and starting families. These are important determinants that facilitate health and wellbeing as well as integration into society (28). Obtaining Australian citizenship was an important driver that informed identity, conferring civic rights and evoking a strong sense of obligation to contribute to the economy, community and country, consistent with other research (51).

Most participants had formed or were in the process of forming their own family, a situation where bicultural identity tends to be significant. A striking theme was the consideration of how culture and identity would be passed on (and change shape) for their children.

Social connections within the community were viewed as an important support base that could be leveraged to promote integration and realise contribution to Australia, facilitating cohesion and promoting health for individuals and community. However, achieving integration and a full sense of belonging was eroded by how this community is perceived in Australia. Experiences of racism, discrimination (direct and indirect) and a sense of 'otherness' generated a questioning of identity and 
belonging. The well-recognised destructive health impacts of racism and discrimination (52-55) were layered on the legacy of refugee experiences in our study.

The diverse contexts in which participants in this study described identity highlight its dynamic nature, which evolves and reshapes to reflect individual situations in time, place and context. Resources and structures needed for integration identified in this study mirror those defined by Ager and Strang (28), and shape the concept of identity. Based on the narratives in this study, building identity is a two-way interplay involving the receiving community and the South Sudanese community in Australia. Therefore, it is important to consider the impacts of the receiving community on identity construction, particularly in providing environments, structures and resources to better support integration and acculturalisation. It is critically important to consider the complexities, nuances, and determinants of identity construction among the South Sudanese community in Australia when working with their community.

\section{Strengths and limitations}

Most studies of refugee experience in resettlement focus on trauma and migration. Our study examined the lived experiences for South Sudanese migrants over time, highlighting the evolving and often conflicting factors that shaped domains of integration and identity construction.

While most participants referred to employment, there was a lack of specific reference to occupation type by most. Similarly, interview questions did not address health, of which there were tangential (mostly mental health) references only by participants.

There was representation of seven women in our study; however, there were no strong gender-based themes in relation to themselves. This may have been influenced by the interviewer, who was male; and by the nature of the interview guide questions.

It was assumed that there may be challenges in recruiting participants from this community related to trust; however, this may have been mitigated by the recruitment process (which involved contacting community leaders and other key stakeholders first), and the fact that the interviewer was South Sudanese, which may have supported a sense of safety. Using community-based recruitment strategies rather than service providers gave a breadth to participant involvement, who included both those who do and do not normally use social services. The impact of COVID necessitated the conducting of interviews via phone for all but six participants, with its associated potential challenges and benefits (56).

\section{Conclusion}

This exploration of lived experiences among South Sudanese refugees in Sydney, Australia found that identity construction was impacted by an array of interconnected determinants that governed the negotiating and making sense of identity. It provides a hitherto unavailable understanding of how South Sudanese see themselves and understand their identity over time in the context of migration to Australia. 
The deeper, more nuanced understandings of bicultural identity within a strength-based framework calls for enhanced investment, better partnerships and services to support capacity - particularly in workforce settings - and participation in Australian life to the greatest extent by South Sudanese and other refugees.

\section{Declarations}

\section{Ethics approval and consent to participate}

Ethical approval for the study was granted by the Human Research Ethics Committee of Central Queensland University (Approval Number: 22101). All face-to-face participants provided written consent before taking part in the interview. However, when social distancing regulations were introduced in Sydney because of COVID-19, the ethics application was modified to allow for data collection and verbal consent given over the phone prior to interviewing.

\section{Consent for publication}

Before commencing the interviews, issues relating to confidentiality, data anonymising, and opting out of the study were reviewed with participants.

\section{Availability of data and materials}

The datasets generated and/or analysed during the current study are not publicly available due to privacy concerns.

\section{Competing interests}

No competing interests to declare by any author.

\section{Funding}

Funding is gratefully acknowledged from the Research Office of Central Queensland University. The funder had no role in the study design, data collection and analysis, decision to publish, or preparation of the manuscript.

\section{Authors' contributions}

Geraldine Vaughan: Conceptualisation, methodology, data analysis, writing - original draft, editing and article preparation. Tafadzwa Nyanhanda: Conceptualisation, methodology, data analysis, writing, editing and article preparation. Sabitra Kaphle: acquisition and interpretation of research data, critical revision for 
important intellectual content. Jenny Kelly: interpretation of research data; Lal Rawal: interpretation of research data; critical revision for important intellectual content. William Mude: Acquisition of research data, conceptualisation, methodology, data analysis, writing, editing and article preparation.

All authors accept responsibility for the paper as published.

\section{Acknowledgements}

We acknowledge the South Sudanese community: those who supported the research through disseminating information about the study, and the participants who have contributed so generously with their time and thoughtful perspectives. Thank you.

\section{Reference}

1. Phinney JS, Ong AD. Conceptualization and measurement of ethnic identity: Current status and future directions. Journal of Counseling Psychology. 2007;54(3):271-81.

2. Walker MH, Lynn FB. The Embedded Self. Social Psychology Quarterly. 2013;76(2):151-79.

3. Cohen JA, Kassan A. Being in-between: A model of cultural identity negotiation for emerging adult immigrants. American Psychological Association; 2018. p. 133-54.

4. Schwartz S, Birman D, Benet V, Unger J. Biculturalism: Negotiating Multiple Cultural Streams. 2016.

5. Schwartz SJ, Unger JB. Biculturalism and Context: What Is Biculturalism, and When Is It Adaptive?: Commentary on Mistry and Wu. Hum Dev. 2010;53(1):26-32.

6. Noels KA, Clément R. Situational variations in ethnic identity across immigration generations: Implications for acculturative change and cross-cultural adaptation. Int J Psychol. 2015;50(6):45162.

7. Mude W, Mwanri L. Negotiating Identity and Belonging in a New Space: Opportunities and Experiences of African Youths in South Australia. International Journal of Environmental Research and Public Health. 2020;17(15):5484.

8. Arends-Tóth J, van de Vijver FJR. Domains and dimensions in acculturation: Implicit theories of Turkish-Dutch. Elsevier Science; 2004. p. 19-35.

9. Doucerain M, Dere J, Ryder A. Travels in hyper-diversity: Multiculturalism and the contextual assessment of acculturation. International Journal of Intercultural Relations. 2013;37:686-99.

10. Birman D, Simon CD, Chan WY, Tran N. A life domains perspective on acculturation and psychological adjustment: a study of refugees from the former Soviet Union. Am J Community Psychol. 2014;53(1-2):60-72.

11. Gagliardi J, Brettschneider C, König H-H. Health-related quality of life of refugees: a systematic review of studies using the WHOQOL-Bref instrument in general and clinical refugee populations in the community setting. Conflict and Health. 2021;15:1-14. 
12. Niemi M, Manhica H, Gunnarsson D, Ståhle G, Larsson S, Saboonchi F. A Scoping Review and Conceptual Model of Social Participation and Mental Health among Refugees and Asylum Seekers. International Journal of Environmental Research and Public Health. 2019;16(20).

13. Bolger DD. Race politics : Australian government responses to asylum seekers and refugees from White Australia to Tampa. Sydney: Western Sydney University; 2016.

14. Cohealth, TACSI. Improving Outcomes with South Sudanese Australians. Melbourne: Victorian State Government; 2018.

15. Huynh K, Neyland S. Australian Whiteness and Refugee Politics. Australian Journal of Politics \& History. 2020;66(1):111-29.

16. Losoncz I. The connection between racist discourse, resettlement policy and outcomes in Australia: Social Alternatives; 2017. 37-42 p.

17. Maley W. Australia's refugee policy: domestic politics and diplomatic consequences. Australian Journal of International Affairs. 2016;70(6):670-80.

18. Bhugra D. Migration, distress and cultural identity. British Medical Bulletin. 2004;69(1):129-41.

19. Bhugra D, Becker MA. Migration, cultural bereavement and cultural identity. World Psychiatry. 2005;4(1):18-24.

20. Abur W, \& Spaaij, R. Settlement and employment experiences of South Sudanese people from refugee backgrounds in Melbourne, Australia. The Australasian Review of African Studies. 2016;37(2):107-28.

21. Abur W. A study of the South Sudanese refugees' perspectives of settlement in the western suburbs of Melbourne. Melbourne, Australia: Victoria University; 2012.

22. Mitchell J, Kaplan I, Crowe L. Two cultures: one life. Community Development Journal. 2006;42(3):282-98.

23. Macaulay L. Australian Sudanese and South Sudanese Youths' Perspectives on the Youth/Parent Relationship and Its Influence on the Transition to Adulthood. YOUNG. 2021;29(2):137-56.

24. Dhanji S. Social or Unsocial? The Linkage Between Accommodation, Health and Well-Being Among Former Horn of Africa and Sudanese Refugees Living in Australia. The Australasian Review of African Studies. 2009(December).

25. Majavu M. The 'African gangs' narrative: associating Blackness with criminality and other anti-Black racist tropes in Australia. African and Black Diaspora: An International Journal. 2020;13(1):27-39.

26. Nolan D, Burgin A, Farquharson K, Marjoribanks T. Media and the politics of belonging: Sudanese Australians, letters to the editor and the new integrationism. Patterns of Prejudice. 2016;50(3):25375.

27. Benier K, Wickes R, Moran C. 'African gangs' in Australia: Perceptions of race and crime in urban neighbourhoods. Journal of Criminology. 2021;54(2):220-38.

28. Ager A, Strang A. Understanding Integration: A Conceptual Framework. Journal of Refugee Studies. 2008;21(2):166-91. 
29. Gibbs L, Snowdon E, Block K, Gallagher HC, Macdougall C, Ireton G, et al. Where do we start? A proposed post-disaster intervention framework for children and young people. Pastoral Care in Education. 2014;32(1):68-87.

30. Smit R. 'Trying to Make South Africa My Home': Integration into the Host Society and the Well-being of Refugee Families. Journal of Comparative Family Studies. 2015;46(1):39-55.

31. Squires P. A scoping review of Australian studies of refugee integration: Popular definitions of integration in the Australian literature. Migration Studies. 2020;8(1):90-112.

32. Rezaei O, Adibi H, Banham V. Integration Experiences of Former Afghan Refugees in Australia: What Challenges Still Remain after Becoming Citizens? International Journal of Environmental Research and Public Health. 2021;18(19):10559.

33. ABS. Data by region Canberra2020 [Available from: https://dbr.abs.gov.au/region.html? lyr=aus\&rgn $=036$.

34. ABS. 2016 Census Data Summary: Cultural Diversity in Australia. Canberra; 2017.

35. ABS. Estimated resident population, Country of birth, State/territory, Age and sex - as at 30 June 1996 to 2016, Census years. Canberra; 2020.

36. Liamputtong P. Qualitative Research Methods (5th ed). Melbourne Vic, Australia: Oxford University Press; 2019.

37. Au M, Anandakumar AD, Preston R, Ray RA, Davis M. A model explaining refugee experiences of the Australian healthcare system: a systematic review of refugee perceptions. BMC International Health and Human Rights. 2019;19(1).

38. WHO. Report on the health of refugees and migrants in the WHO European Region Geneva2019 [

39. Verwiebe R, Kittel B, Dellinger F, Liebhart C, Schiestl D, Haindorfer R, et al. Finding your way into employment against all odds? Successful job search of refugees in Austria. Journal of Ethnic and Migration Studies. 2019;45(9):1401-18.

40. Correa-Velez I, Barnett AG, Gifford S. Working for a Better Life: Longitudinal Evidence on the Predictors of Employment Among Recently Arrived Refugee Migrant Men Living in Australia. International Migration. 2015;53(2):321-37.

41. Wood N, Charlwood G, Zecchin C, Hansen V, Douglas M, Pit SW. Qualitative exploration of the impact of employment and volunteering upon the health and wellbeing of African refugees settled in regional Australia: a refugee perspective. BMC Public Health. 2019;19(1).

42. Mude W, Mwanri L. Barriers to Participation in Physical Activity Among South Sudanese Children in South Australia: Parents' Perspectives. Fam Community Health. 2016;39(4):293-300.

43. Lovink AR. The Adaptation of South Sudanese Christian Refugees in Ottawa, Canada: Social Capital, Segmented Assimilation and Religious Organization: U Ottawa; 2010.

44. Stewart M, Dennis CL, Kariwo M, Kushner KE, Letourneau N, Makumbe K, et al. Challenges Faced by Refugee New Parents from Africa in Canada. Journal of Immigrant and Minority Health. 2015;17(4):1146-56. 
45. Woodgate RL, Busolo DS. African Refugee Youth's Experiences of Navigating Different Cultures in Canada: A "Push and Pull" Experience. Int J Environ Res Public Health. 2021;18(4).

46. Newbold KB, McKeary M. Journey to Health: $(\mathrm{Re})$ Contextualizing the Health of Canada's Refugee Population. J Refug Stud. 2018;31(4):687-704.

47. Lamba NK. The Employment Experiences of Canadian Refugees: Measuring the Impact of Human and Social Capital on Quality of Employment*. Canadian Review of Sociology/Revue canadienne de sociologie. 2008;40(1):45-64.

48. Newman A, Bimrose J, Nielsen I, Zacher H. Vocational Behavior of Refugees: How do Refugees Seek Employment, Overcome Work-related Challenges, and Navigate Their Careers? Journal of Vocational Behavior. 2018;105:1-5.

49. Wehrle K, Klehe U-C, Kira M, Zikic J. Can I come as I am? Refugees' vocational identity threats, coping, and growth. Journal of Vocational Behavior. 2018;105:83-101.

50. Shergold P, Benson K, Piper M. Investing in Refugees, Investing in Australia: The findings of a Review into Integration, Employment and Settlement Outcomes for Refugees and Humanitarian Entrants in Australia. In: Department of the Prime Minister and Cabinet, editor. Canberra: Commonwealth of Australia; 2019.

51. UNHCR. The Impact of Government-Sponsored Refugee Resettlement: A Meta Study of Findings from Six Countries. Geneva, Switzerland: Office of the United Nations High Commissioner for Refugees (UNHCR); 2020.

52. Williams DR, Lawrence JA, Davis BA. Racism and Health: Evidence and Needed Research. Annual Review of Public Health. 2019;40(1):105-25.

53. Thorpe JRJ. Foreword: Racism and Health. Ethnicity \& Disease. 2020;30(3):369-72.

54. Elias A, Paradies Y. The Costs of Institutional Racism and its Ethical Implications for Healthcare. Journal of Bioethical Inquiry. 2021;18(1):45-58.

55. Ziersch A, Due C, Walsh M. Discrimination: a health hazard for people from refugee and asylumseeking backgrounds resettled in Australia. BMC Public Health. 2020;20(1).

56. Saarijärvi M, Bratt E-L. When face-to-face interviews are not possible: tips and tricks for video, telephone, online chat, and email interviews in qualitative research. European Journal of Cardiovascular Nursing. 2021;20(4):392-6.

\section{Figures}




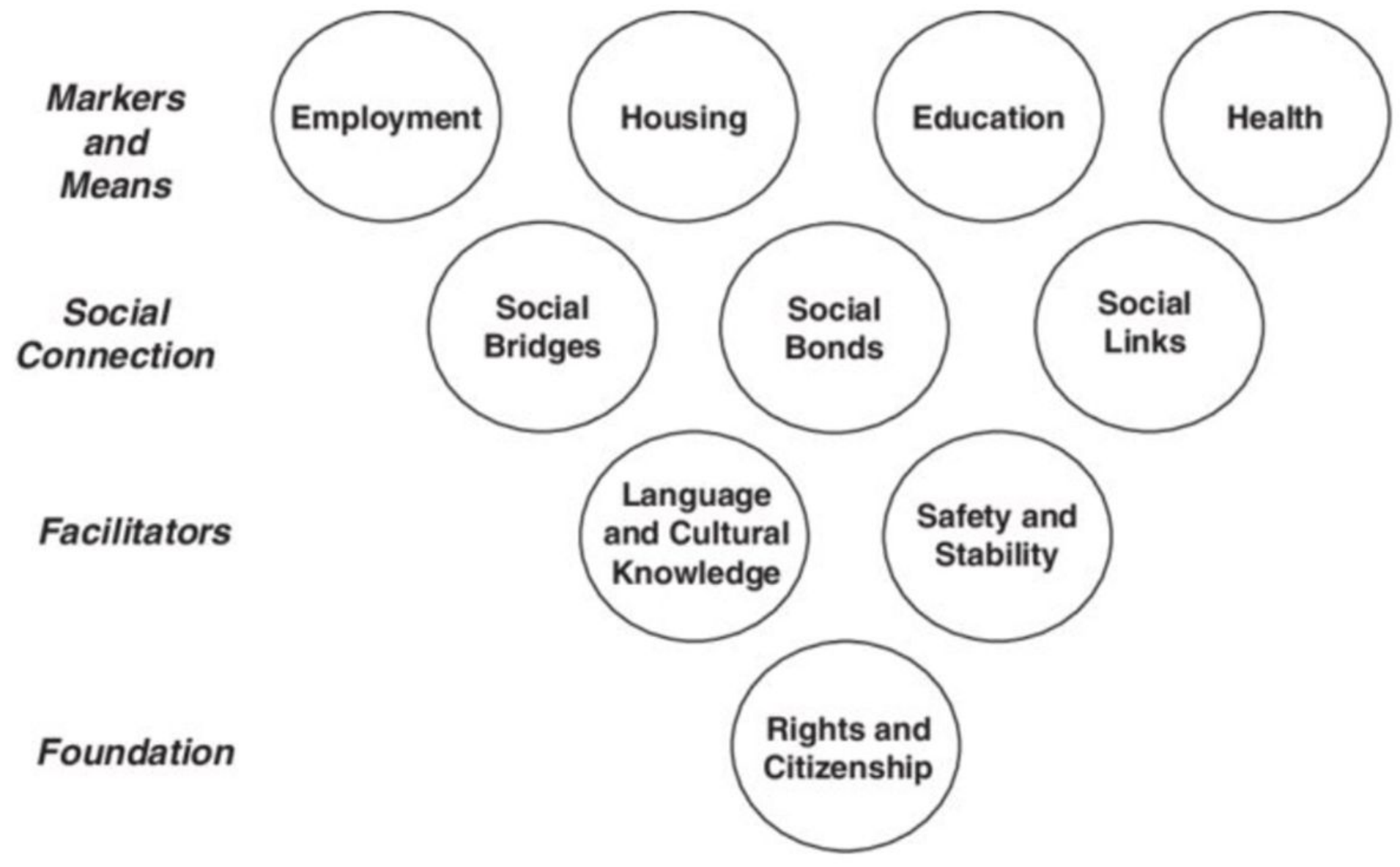

Figure 1

Conceptual framework defining core domains of integration 


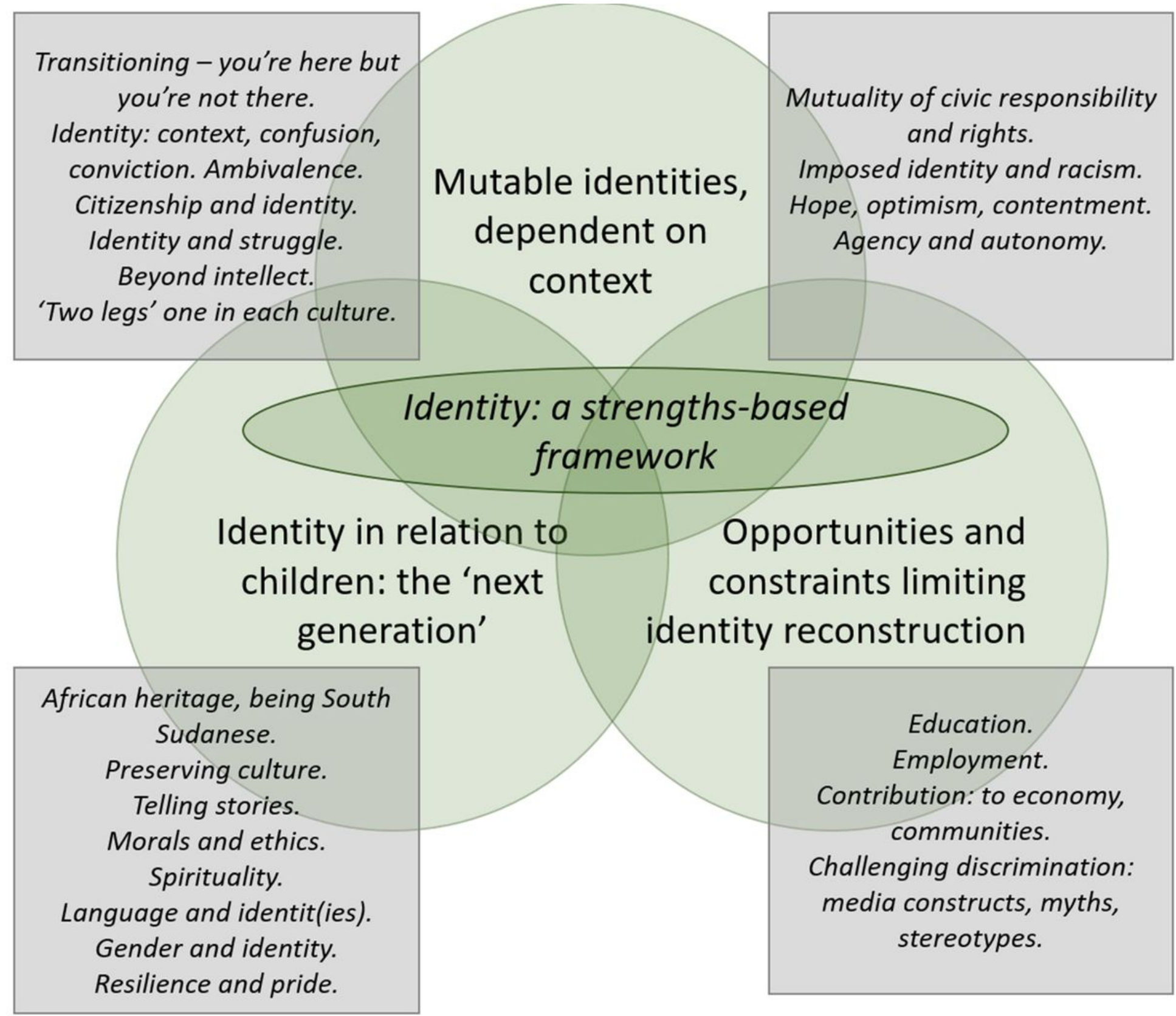

Figure 2

Interconnected domains governing the making sense of identity

\section{Supplementary Files}

This is a list of supplementary files associated with this preprint. Click to download.

- REVISEDInterviewGuide29Jan2020.docx 